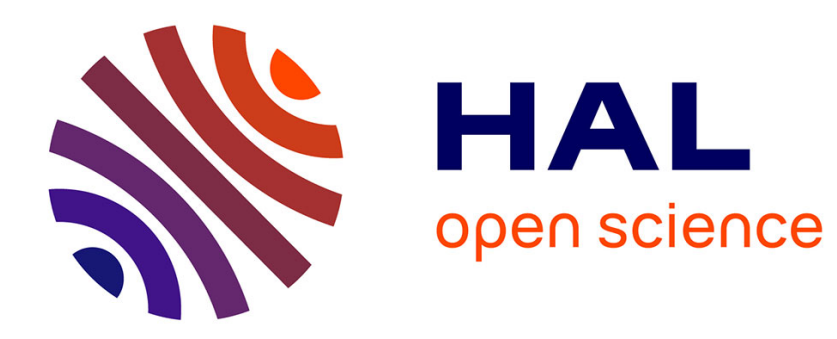

\title{
New forms of intellectual activity in globalized society Sergey Kulikov
}

\section{To cite this version:}

Sergey Kulikov. New forms of intellectual activity in globalized society. foresight, 2021, ahead-of-print (ahead-of-print), 10.1108/FS-05-2021-0104 . hal-03471898

\section{HAL Id: hal-03471898 \\ https://hal.science/hal-03471898}

Submitted on 24 Dec 2021

HAL is a multi-disciplinary open access archive for the deposit and dissemination of scientific research documents, whether they are published or not. The documents may come from teaching and research institutions in France or abroad, or from public or private research centers.
L'archive ouverte pluridisciplinaire HAL, est destinée au dépôt et à la diffusion de documents scientifiques de niveau recherche, publiés ou non, émanant des établissements d'enseignement et de recherche français ou étrangers, des laboratoires publics ou privés. 


\title{
New Forms of Intellectual Activity in Globalized Society ${ }^{1}$
}

\author{
Sergey B. Kulikov \\ DSc in philosophy, Director of Science and Education Center for Humanities \\ Tomsk State Pedagogical University \\ 634061 Tomsk, Kievskaya St., 60 \\ Correspondent author e-mail: kulikov.sergh@gmail.com
}

\section{Author Bio}

Dr. Sergey B. Kulikov currently works at the Science and Education Center for Humanities, Tomsk State Pedagogical University. He is a graduate of Tomsk State University, where he received B.A. in Philosophy (2000), Specialist Philosophy Teacher (2001) and PhD in philosophy (2004). Dr. Kulikov received DSc in philosophy in Tomsk State Pedagogical University in 2012. Presently, Dr. Kulikov does research in Metaphysics, Logic, History and Philosophy of Science and History of Education. His most recent publications are 'Scientific Ethos and Foundations of Conscious Activity' (Integr. psych. behav. 54, 158-178 (2020). https://doi.org/10.1007/s12124-019-09483-6), 'Artificial intelligence, culture and education.' (AI \& Soc 36, 305-318 (2021). https://doi.org/10.1007/s00146-020-01026-7), and 'Epistemic Relativism, Probability, and Forms of Subjectivity.' (Axiomathes (2021). https://doi.org/10.1007/s10516-021-09565-4)

\footnotetext{
${ }^{1}$ This paper presents Author Accepted Manuscript (AAM) published online in Foresight, Vol. ahead-of-print No. ahead-of-print. DOI : https://doi.org/10.1108/FS-05-2021-0104 Author deposits the AAM under the Creative Commons Attribution Non-commercial International Licence 4.0 (CC BY-NC 4.0). To reuse the AAM for commercial purposes, permission should be sought by contacting permissions@ emeraldinsight.com
} 


\title{
New Forms of Intellectual Activity in Globalized Society
}

\begin{abstract}
Design/methodology/approach. This research examines the ways of predicting the development of intellectual activity. To reveal the topic, the author uses semiotics and the method of building possible worlds. The author explores intellectual activity in terms of sign systems. From this angle, the logic of the narrative expresses the order of the organization of intellectual activity. This approach reveals the connections between images of possible worlds and decision-making methods. Purpose. The purpose of this article is the foresight of new forms of intellectual activity in society. Findings. The author conceptually outlines the forms of intellectual activity in a globalized society. A globalized society is a complex of political, economic, cultural, and scientific ties that spread throughout the world. The foresight of new forms of intellectual activity allows conceptually sketching the practical use of proper decision-making methods. These methods involve the use of artificial machine intelligence, collective intelligence, etc. Forms of intellectual activity are related to the worldbuilding that cause the development of culture through the development of knowledge. The description of forms of intellectual activity shows a promising way of humanitarian research in a globalized society.
\end{abstract}

Research limitations/implications. The research implies technological metaphors related to the history of culture and the role of intellectual activity in it.

Practical implications. The author examines the practical possibilities of applying traditional humanities for the development of new forms of intellectual activity in a globalized society. Social implications. In the social space, exposing the effectiveness of traditional humanities helps to assess the consequences of using intellectual activity in practice.

Originality/value. The originality of the research is associated with the identification of links between the conceptual provisions of semiotics and the method for building possible worlds. Key words: 
Foresight; Globalized Society; Communication; Intellectual Activity; Collective Intelligence 


\section{New Forms of Intellectual Activity in Globalized Society}

\section{Introduction}

This research examines new forms of intellectual activity in a globalized society. A globalized society is a complex of political, economic, cultural, and scientific ties that spread throughout the world (Bauman 1998; Giddens 2002; Donati 2013). The forms of intellectual activity become a reflection of decision-making methods. These methods affect the transformation of the world into a space of global communication and interaction. The research of new forms of intellectual activity thus brings an answer to the question of the patterns that make transformed communication and interaction more successful and productive.

In order to outline the forms of intellectual activity in a globalized society, it is necessary to clarify the meaning of intellectual activity as such. The author of this article refers to the concept of 'discursive power of thinking' in Steel (2012). This concept is originally devoted to a discussion of medieval contemplative taxonomy. Given the background, Steel (2012) discusses intelligence and intellectual activity in terms of Aristotelian philosophy. Medieval taxonomies, however, ensure the possibility of interpreting the intellectual activity of people as one of the types of such activity. As manifestations of the discursive power of thinking, other types of intellectual activity characterize supernatural beings, namely, angels, demons, and God. Medieval taxonomies help to find fundamental differences in the skills of intellectual activity agents. In a modern globalized society, the types of intellectual activity are still diverse. They are related to machine intelligence, collective intelligence, swarm intelligence, etc. (Fisher and Fisher 1997; Levy 1999; Segaran 2007; Calderón and Rainer 2014; Tangen et al. 2020; Peters 2021). Meanwhile, the author of this article does not mean the substantive similarity of the forms of intellectual activity in a globalized society and in the Middle Ages. Nonetheless, structurally, the new types of intellectual activity show forms of human and non-human intelligence, the same as the medieval forms. Therefore, the concept of the discursive power of thinking is useful for clarifying the types of intellectual activity and their transformations in a modern globalized society. 
In a globalized society, transformations of intellectual activity constantly generate controversies, especially in the field of the role of intellectual activity in the organization and management of society (Kulikov 2016a; Ikenberry and Nexon 2019; Eilstrup-Sangiovanni and Hofmann 2020; Flockhart 2020; Kavalski 2020; Kurki 2020). The issue of intellectual activity is related to the issue of decision-making. To reveal the methods of decision-making in a globalized society, the author turns to the semiotic interpretation of the connections between culture and rationality or selfgenerating logos in Lotman et al. (1978). The interpretation of intellectual activity in terms of the discursive power of thinking is also related to the method of building possible worlds (Menzies and Pettit 1994; Slaughter 2002; Zaidi 2019; Fischer and Menert 2021) and its theoretical foundations in modal logic (Kripke 1980). This interpretation allows standing for the intellectual activity and society in terms of modeling and fiction making (Frigg 2010). In addition, the research belongs to the field of modern studies in which Salis (2010) and Alward (2011) discuss the status of fictional names and fictional reports. As a result, the approaches used in this research help to predict and assess the trends of intellectual activity in a modern globalized society.

The substantive part of this article includes two sections. Sect. 1 shows the theoretical reflections on intellectual activity and its transformation in modern society. Sect. 2 examines the practical use of new forms of intellectual activity in a globalized society through education.

\section{Research Design and Methodology}

This research examines the theoretical methods of forecasting the development of intellectual activity in society. From this angle, intersection of science and education becomes a field of comparison of different methods of decision-making. Forecasting trends in intellectual activity helps to show the effectiveness of the humanities in social research along with the use of digital technologies. Digital technologies show their usefulness in education (Konrad and Monroe 2008; Kovanovich et al. 2015; Zawacki-Richter et al. 2019; Ketko 2020). The author of this article clarifies the limits of the application of traditional humanities in this field. 
To clarify the limits of the application of traditional humanities, the author turns to semiotics (Lotman et al. 1978) and method of building possible worlds (Zaidi 2019; Fischer and Mehnert 2021). Semiotics ensures the consideration of intellectual activity in terms of sign systems. Semiotic representation reveals trends in the development of intellectual activity concerning the images of society and its future. The interpretation of sign systems as texts about the future ensures the use of the method of building possible worlds. This method is associated with the composing the narratives according to basic rules, namely, (i) the use of speculations in worldbuilding, and (ii) a reflexive attitude to the images of the future. The use of elements of the approaches by Bentham (cf. Ogden 1932) and Vaihenger (1910/1968) expands the possibilities of this procedure. As a result, the understanding intellectual activity in terms of the order of building possible worlds helps to conduct research in the framework of studying the images of the future.

\section{Theoretical Reflections on Intellectual Activity and Its Transformation in Modern Society}

This section examines current trends in the development of intellectual activity in the order as follows:

- revealing the transformation of intellectual activity according to changes in the general understanding of intelligence

- disclosing the development of intellectual activity in terms of building possible worlds and ordering behavior in culture

This section includes two subsections.

\subsection{Intellectual Activity and Its Transformation}

In this subsection, the research of the transformation of intellectual activity in a globalized society involves consideration of two points, namely, (i) a general understanding of intellectual activity in terms of the discursive power of thinking (Steel 2012), and (ii) a semiotic explanation of processes in social and cultural systems (Lotman et al. 1978). 
A general understanding of intellectual activity requires considering important nuances. Various models of intelligence and its evolution are proposed in cognitive sciences (cf. development from Cronbach (1957) to Hunt $(2006 ; 2010))$. However, there is no generally accepted answer to the question about the differences between types of intellectual activity yet. Given the background, modern scholars do not follow the ancient and medieval intentions to consider human intelligence as a part of the Cosmos or a manifestation of Divine Forces. Meanwhile, after Steel (2012), the author of this article suggests the significance of the concept of the discursive power of thinking associated with medieval ideas about intelligence. This concept can be a framework for distinguishing artificial machine intelligence and natural human intelligence. The forms of intellectual activity associated with modern types of intelligence are structurally related to medieval forms of intelligence and intellectual activity. Each type of intelligence fingers out specific options for discursive thinking. A comparison of these options helps to find common features of intellectual activity in general.

In a globalized society, the comparison of intellectual activity options should begin with clarifying the characteristics of activities based on artificial machine intelligence. These are the most advanced forms of intellectual activity in modern society. Machine intelligence models are built using logical and mathematical algorithms (cf. Feldman and Domshlack 2014; Gent 2013; Kotthoff 2014; Metcalf et al. 2019). This is a digital or computational way of thinking, which is expressed in the corresponding type of intelligence. The actions of digital or computational intelligence figure out the decision-making in the set $[1,0]$, when the machine distinguishes between the possible (1) and the impossible (0). For instance, suggest that the algorithm ensures a selection of white and black items in a box. Based on this algorithm, the machine should necessarily select a white or black item, distinguishing it from items of another color. Nonetheless, take the case when a particular box holds only black items. In this case, the machine has to stop making decisions due to the breaking the selection parameters. The machine itself cannot spontaneously change the underlying algorithm. In turn, human intelligence is associated with decision-making based on choice that relates to sorting 
through alternatives in the range from 0 to 1 without excluding uncertainty $(1 / 2,1 / 4$, etc.). Human can change the algorithm of intellectual actions if this algorithm seems incorrect or incomplete for making-decision. This is an analogue way of thinking. As a result, the main difference between the types of intellectual activities based on artificial machine intelligence and natural human intelligence coincides with the logic of decision-making and degrees of freedom in the use of underlying algorithms. The dependence of intellectual activities on decision-making algorithms as such is a common feature of certain types of these activities.

In the course of revealing intellectual activity in a globalized society, the author refers to signs and sign systems. It involves relying on a semiotic interpretation of intellectual activity. The author prefers to apply semiotics within the framework of the approach developed by Lotman et al. (1978) and Lotman and Clark (2005). This preference is due to the following reasons. Saussure $(1916 / 1997)$ and Peirce $(1867 ; 1891 / 1892)$ conduct early research in the field of semiotics. Barthes (1957), Eco (1976), Baudrillard (1983) and others continue this line of research. Meanwhile, Lotman gives interesting arguments that help to consider the forms of intellectual activity in a globalized society in a new way. In particular, Lotman and Clark (2005) mention as follows: ...the individual act of sign exchange has come to be regarded as a model of natural language, and models of natural languages as universal semiotic models, whereas semiotics itself has sought to be understood as the extension of linguistic methods to objects not included in traditional linguistics. (Lotman and Clark 2005, 206).

Lotman and Clark (2005) show the possibility of analyzing cultural phenomena through their language expression. From a semiotic perspective, each type of social and cultural practices - art, education, science, etc. - supplies replacement of natural objects by secondary models in various semiotic systems. This is important for finding rules that organize behavior and communication of people in culture and society. For instance, traffic signs schematically express vehicles rules and ensure tracking of the accuracy or inaccuracy of decisions made by drivers. This particular case helps to show a significant pattern in general. The forms of organization of behavior and 
communication are related to the basic principles of intelligence, as they express the methods of decision-making. In general, semiotics supplies research of decision-making methods in accordance with language forms of expression of intellectual activity behind these methods in culture.

As for the globalized society, the analysis of the logic of sign systems can highlight the parameters of intellectual activity in this society. These parameters are associated with the expression of globalization processes. In particular, narrative is a kind of sign systems that express the development of behavior and communication in a globalized society in a compressed form. As a result, systematization of modeling tools for semiotic analysis of intellectual activity helps to highlight new forms and trends in development of this activity in modern society.

\subsection{Culture, Development of Intellectual Activity and Possible Worlds}

In this subsection, identification of trends in the development of intellectual activity concerns the disclosure of the relationships between intellectual activity, the ordering of behavior in culture, and building possible worlds. In a globalized society, these relationships refer to the generation and use of new forms of communication and associated sign systems. The interpretation of modern rationality through semiotic statements about social and cultural phenomena helps to explain sign systems in terms of the rules of organization of narratives. For instance, in the past, the narrative about the participation of transgender athletes in the Olympic Games could be presented as fictional. In the present, this narrative reveals the real state of affairs (cf. Hilton and Lundberg 2021). In turn, the current assumptions about the participation of robot athletes along with living beings look like a science fiction story (Faris 2019). Nonetheless, such a decision corresponds to the logic of modern decision-making methods aimed at supporting social well-being in a globalized world. Moreover, this case helps to show the difference between traditional forms of intelligence, namely, individual decision-making due to common sense in opposite to new forms, in particular collective intelligence (Levy 1999, 14). In combination with the emerging intellectual skills, new forms of intellectual activity correlate with the idea of a joint venture to build a possible world. This 
procedure is associated with the rules of composing narratives, namely, (i) the use of speculations in worldbuilding, and (ii) a reflexive attitude to the images of the future (Fischer and Mehnert 2021). The interpretation of intellectual activity in terms of building possible worlds correlates with the image of culture suggested by Lotman et al. (1978). Lotman et al. (1978) mention as follows: ...culture must have within itself a structural 'diecasting mechanism'. It is this function that is performed by natural language. It is natural language that gives the members of a social group their intuitive sense of structuredness that with its transformation of the 'open' world of realia into a 'closed' world of names, forces people to treat as structures those phenomena whose structuredness, at best, is not apparent (Lotman et al. 1978, 213).

Lotman et al. (1978) use technological metaphors to describe the basic functions of culture in modern society in terms of a die casting mechanism. The work of this mechanism helps to build one of the possible worlds of culture. Lotman et al. (1978) mention as follows:

Culture can be presented as an aggregate of texts; however, from the point of view of the researcher, it is more exact to consider culture as a mechanism creating an aggregate of texts and texts as the realization of culture. ... In contrasting text and rules, as applied to culture, it is also important to keep in mind that, in some cases, the same elements of a culture can serve both functions, that is, both as text and as rules. (Lotman et al. 1978, 218).

Lotman et al. (1978) show that the concept of a cultural die casting mechanism ensures a modern way to show the building the world of culture in which texts and their building rules coincide. In this regard, the opposition between the organization and entropy or chaos is revealed. Forms of culture are ways of organization for any next forms and manifestations of chaos for any preceding forms. For instance, Kulikov (2016b) shows this process by the example of the relationship between ancient Egyptian and Hellenistic culture in the Ptolemaic kingdom. 
Lotman's concept reveals culture as a kind of memory storage but not just as a die casting mechanism. In this regard, the semiotic interpretation of culture is related to the question about the rules for organizing cultural experience in textual form. Lotman et al. (1978) mention as follows:

While it is typical of some cultures to regard themselves as an aggregate of normative texts (take the Domostroy, for example), others model themselves as a system of rules that determine the creation of text (Lotman et al 1978, 218).

In fact, Lotman et al. (1978) show the relationship between the norms and rules set out in texts and the types of intellectual activity that affects the creation of texts. From this angle, the following statements become justified:

Each type of culture generates its own particular ideal of Book and Manual, including the organization of those texts. Thus, with orientation towards rules, a manual has the appearance of a generative mechanism, while with orientation towards text, one gets the characteristic (question-answer) format of a catechism, and the anthology (book of quotations or selected texts) comes into being ... a necessary minimal condition for the creation of culture, the degree to which they enter into its self-appraisal will vary. This can be compared to the teaching of language as a system of grammatical rules or as a set of usages. (Lotman et al. 1978, 218-219).

As a result, after Lotman et al. (1978), the author of this article shows the value of technological metaphors for description of connections between culture and intellectual activity. In modern society, this way of description is associated with the image of culture considered by analogy with behavioral programming. In the history of culture, texts play the same role as programs for processing data by computers. With this in mind, the author intends to predict the development of new forms of intellectual activity in a globalized society, in particular intellectual activities based on collective (distributed) intelligence. Given the background, intellectual activity relates to the production of different stories by the rules of fiction making (cf. Goody 2010). These stories 
describe possible worlds and express dependence on the type of intellectual activity behind the building these worlds.

\section{Forecasting Practical Use of Intellectual Activity in Globalized Society}

This section examines the practical use of new forms of intellectual activity in a globalized society. As the basic element of the cultural die casting mechanism, intellectual activity in a globalized society becomes a generator of new types of communication and the basis for building possible worlds. The author's argument involves the points as follows:

- ensuring support for the semiotic interpretation of intellectual activity and the use of the method for building possible worlds related to the generation of rationality in modern culture

- assessing the application of intellectual activity due to the use of collective intelligence in the transferring narratives in science and education

This section includes two subsections.

\subsection{Intellectual Activity, Semiosphere and Building Possible Worlds}

This subsection examines the relationships between the concepts of intellectual activity, semiosphere and the building possible worlds. Lotman and Clark (2005) propose the concept of the semiosphere to describe the production of rationality. Semiosphere or 'semiotic universe' is almost similar to the noosphere, the highest level of the biosphere introduced by Vernadsky (1945). Meanwhile, the noosphere is a geological phenomenon. In particular, Vernadsky (1945) mentions as follows:

The noosphere is a new geological phenomenon on our planet. In it for the first time man becomes a large-scale geological force (Vernadsky 1945, 9).

In turn, Lotman and Clark (2005) mention as follows:

It may now be possible to suggest that, in reality, clear and functionally mono-semantic systems do not exist in isolation. ... They function only by being immersed in a specific 
semiotic continuum, which is filled with multi-variant semiotic models situated at a range of hierarchical levels. Such a continuum we, by analogy with the concept of 'biosphere' introduced by V. I. Vernadsky, will call the 'semiosphere'. We must, however, warn against any confusion between the term 'noosphere' used by V. I. Vernadsky and the concept of 'semiosphere' here introduced. ... Vernadsky's biosphere is a cosmic mechanism, which occupies a specific structural place in planetary unity. ... The semiotic universe may be regarded as the totality of individual texts and isolated languages as they relate to each other. In this case, all structures will look as if they are constructed out of individual bricks (Lotman and Clark 2005, 206208).

It is easy to show that the semiosphere is a social and cultural phenomenon by its own specifics. From this angle, the semiosphere relates to the formation of signs and sign systems that are associated with the forms of intellectual activity behind. In turn, intellectual activity corresponds to different versions of the works of the die casting mechanism of culture (Lotman et al. 1978). This approach helps to find key factors that affect the use of intellectual activity in a globalized society. In addition, the interpretation of culture in terms of the semiosphere and the die casting mechanism reveals the processes of generating forms of rationality as options for building possible worlds. To reveal one of the cases of building possible worlds, the author considers two alternative worlds $\mathrm{W}_{1}$ and $\mathrm{W}_{2}$ in which Russia exists $\left(\mathrm{W}_{1}\right)$ or does not exist $\left(\mathrm{W}_{2}\right)$. The first world shows the control of one national state over $1 / 8$ of the Earth's territory. In this world, the Russian Federation is an intermediary for the European Union and China. The second world stands for the situation of the absence of an intermediary. In the first world, the natural resources in Siberia are under control of the Russian Federation. In the second world, these resources are the object of conflict between regional superpowers. Using the collective intelligence to consider these alternatives can help to decide on the necessary nature of the sovereign power in the place of the Russian Federation, even if there is no such power. Other decisions threaten to freeze conflicts over natural resources, turning 
these conflicts into a constant danger to international relations. As they say, a bad compromise is better than a good lawsuit.

Given the background, the author of this article shows the connections between the formation of rationality and manifestations of intellectual activity in culture. Intellectual activity becomes the basis for revealing special variants of the relationship between scientific knowledge and education. The author's argument is related to historical facts, for instance, to the significant role of the concepts proposed by Aristotle. These ideas figure out the logic of thinking and the logic of education in the Antiquity and following epochs (Koyre 1966/1985, 30). The reference in this article to the Aristotelian concept of intelligence adopted in the Middle Ages, namely, intelligence as a discursive power of thinking (Steel 2012), is an added confirmation of this inference. Recent studies show similar effects of intellectual activity oriented on creating forms of rationality. Modern advances in the social sciences and humanities cause these effects. For instance, Todt and Luján (2014) reveal the influence of noncognitive values on science. Todt and Luján (2014) mention as follows:

...in the science as arbiter approach, there is the constant question as to the (exclusive) relevance of cognitive values for real-world situations, while under the Science as facilitator approach, the issue is if noncognitive (social) values allow for a sufficient understanding of highly complex and future-oriented decision options. (Todt and Luján 2014, 737).

In current article, the identification of the semiosphere as a generator of rationality patterns helps to show the influence of the humanities on the development of human qualities and skills in a globalized society. These are decision-making actions related to the collective intelligence. From this angle, Ketko (2020) mentions as follows:

The diversity of intelligence, thinking teams, and synergetic work, leading multidisciplinary initiatives and projects, has permeated the education system and teachers' training. However, it is important to conduct an in-depth observation of the 
dynamics of these frameworks, and the place of the individual within them. (Ketko 2020, 4).

Bearing in mind collective intelligence, the dependence of educational practices on the achievements of the humanities ensures a framework for social engineering procedures that help their users. The humanities become knowledge about the development of knowledge through learning. This point shows the effectiveness of the humanities concerning social life.

From a semiotic perspective, the author shows that the humanities can generate specific educational technologies. The humanities achieve two purposes, namely, (i) the development of methodological culture associated with the symbolic role of criticism in science, and (ii) improving the quality of scientific research in general.

In a globalized society, the development of a methodological culture associated with the symbolic role of criticism coincides with a specific concept of the application of intellectual activity. The symbolic role of criticism shows the possibilities for a smart assessment of situations. In this regard, intellectual activity can be correlated with the logic of multi-level assessment systems. Each level refers to the elements of decision-making involved in the complex of collective activity. For instance, the decision-making agent intends to choose the trajectory of the development of trade relations among country A and countries B and C. At the same time, countries B and C are in conflict. Country A does not conflict with either country B or country C. The decision-making agent needs to choose which of the trading partners to prefer, because continuing relations with both partners can lead to a conflict with one of them, or even with both. In this case, the decision-making agent is forced to act within a complex system of critical assessments of the situation. This agent can hide from one of the parties that he/she continues to trade with the other party. It is also possible that one of the trading partners is excluded from the network of relations. However, the most helpful possibility is to enter into relations between $\mathrm{B}$ and $\mathrm{C}$ as an intermediary to resolve their conflict. The nature of the selected decision-making options shows the limits of competence in which decision-making agents is able to act accordingly his/her skill level. In a globalized society, 
this logic is useful due to the presentation of a separate element of decision-making as a special type of self-regulating acts of criticism. From this angle, the logic of decision-making gets the status of a multi-valued system of statements (cf. Fermüller 2008; Frè 2013). The semiotic approach involved in the development of methodological culture can reveal the semantics of these systems.

Semiotic description of the development of methodological culture assumes the comprehension of knowledge in terms of Lotman's concept of semiosphere. It becomes possible to improve the quality of scientific research in general. This purpose can be achieved with respect to specific forms of organization of intellectual activity. The organization of intellectual activity can help to find signs of patterns in the development of scientific knowledge in society. For instance, consider the case of Newton's orientation on Neoplatonic interpretation of space (Slowik 2013). Newton's understanding of space is a reinterpreted sign of an ancient heritage in Modernity. In general, it is an expression of the process of preserving scientific stances and replacing them with new stances by critical attitudes. In this regard, for instance, Darwin's (1859) Theory of Evolution replaces earlier theories that assume the immutability of the types of living beings in nature. Darwin's Theory of Evolution, however, generates controversy in modern science (cf. Depew and Weber 2011). These cases show ways to implement scientific narratives for the application of new forms of intellectual activity and options of collective decision-making in a modern globalized society.

As a result, the author finds that two key factors affect the application of intellectual activity in a globalized society. The first factor corresponds to the complexity of knowledge that helps to clarify the prospects for the development of intellectual activity. This article examines the complexity through the appeal to intersections of semiotics, philosophy, and sociology. The second factor is related to the generation of innovative ideas within the framework of organizational forms of intellectual activity as a way of manifestation of culture. Bearing in mind these factors, it becomes possible to assess the use of forms of intellectual activity in a globalized society.

\subsection{Application of New Forms of Intellectual Activity in Globalized Society and its}

\section{Assessment}


In this subsection, the assessment of applying new forms of intellectual activity concerns the interpretation of these forms in terms of building possible worlds. Given the background, the content of narratives about modern trends depends on the complexity of knowledge requiring intellectual activity based on collective intelligence.

Regarding the concept of narrative, O’Neill (1994) mentions as follows:

...discourse is always potentially subversive of its ostensibly 'natural' role as instrument or vehicle. The emblematic figure in this context is the pre-Socratic philosopher Zeno of Elea, who notoriously demonstrated, precisely by means of a virtuoso flaunting of the possibilities of narrative discourse, that stories we all know to be entirely possible can 'in fact' never take place - an ironic inversion of the more common practice. (O’Neill 1994, 4).

As for the collective intelligence, Segaran (2007) suggests as follows:

Although the expression may bring to mind ideas of group consciousness or supernatural phenomena, when technologists use this phrase they usually mean the combining of behavior, preferences, or ideas of a group of people to create novel insights. (Segaran 2007, 2).

O’Neill (1994) and Segaran (2007) show the correlation of narrative-oriented approach to collective intelligence with three points, namely, (i) group activity, (ii) creative or controversial, or problematic thinking, and (iii) novel insights independent on their direct correlation with facts. The collective intelligence is the basis of intellectual activity, which is associated with the so-called knowledge work. From this angle, Fisher and Fisher (1997) mention as follows:

Knowledge work is activity that frequently produces new knowledge. Its core task is thinking, its outcome is information, it is typically nonlinear in nature, and it requires mental skills to perform successfully. (Fisher and Fisher 1997, 19).

The use of narratives about the cases of the building possible worlds by the collective intelligence can be represented as follows: 
...the participants explored the world through the eyes of their characters and by that reflected upon the desirability of the possible world. During the writing process, we discussed presented assumptions, talked about dystopic and utopic potentials and how technologies need to be actively shaped to help or hinder societal development. (Fischer and Mehnert 2021, 33).

In this way, the author of this article shows correlations between collective intelligence, mental skills, and knowledge. The semiotic approach points out these correlations in terms of sign systems. The use of these sign systems in the framework of worldbuilding narratives helps to predict the consequences of the application of new forms of intellectual activity in modern society. In turn, the implementation of a special procedure helps to achieve the purpose of predicting the consequences of the application of intellectual activity. The procedure is aimed at finding a positive paradoxicity in the field of complexity of knowledge and cultural manifestations. This is due to Deleuze's $(1990,74-81)$ reflections on the logic of sense adopted by the author of this article in relation to Lotman's theory of the semiosphere. As an objection to the requirements of logicians, Deleuze (1990) mentions as follows:

For paradoxes, on the contrary, inhere in language, and the whole problem is to know whether language would be able to function without bringing about the insistence of such entities. (Deleuze 1990, 74).

Deleuze (1990) shows that paradoxes are not identified and eliminated by correctly constructed statements. On the contrary, the sense of sentences is determined by paradoxes. From this angle, paradoxes as such become a sign of the progress of knowledge in a modern globalized society. In the course of the development of the semiosphere, paradoxes are just one of the new results of the die casting mechanism of modern culture.

In a globalized society, the emphasis on two epistemological points presupposes the representation of phenomena associated with positive paradoxicity. The first point coincides with considering the possibilities of the Universalist nature of statements like ' $2+2=4$ ', at least in the decimal reference 
frame. The second point is connected with the constant historical attempts to reject universalism due to the relativism of reference frames and the ambiguity of the limits of intellectual activity. The relativism of reference frames correlated with epistemic relativism is considered in Kulikov (2021). The ambiguity of the limits of intellectual activity is due to the historical development of knowledge. For instance, in the Middle Ages, the limits of intellectual activity are associated with the contraposition of Faith and Reason (Marenbon 2007). In Modernity, these limits are associated with the contraposition of Nature and Humans.

In the context of this research, emerging new ways of intellectual activity are one of the manifestations of a positive paradoxicity in the history of knowledge. It helps to emphasize the cases of building possible worlds in the context of the exchange of narratives about the past, present, and future. The diversity of narratives and their controversial nature reveal the possibilities of the humanities in a globalized society. In modern conditions, there is no unary basic narrative that serves as a prototype for other ways of describing. This inference is justified due to the following interpretation of the history of the humanities through the history of philosophy. Each epoch of philosophical reflection, namely Classical Antiquity, post-classical Middle Ages and Modernity shows key narratives about the Cosmos, God, and Nature (cf. On nature by Heraclitus (Kahn 1979); The Summa Theologiae by Thomas Aquinas (1911); Philosophy of Nature by Hegel (1970)). In this regard, the intentions to take a complete picture are not crowned with success. Philosophers constantly intend to propose new statements about key objects - the Cosmos, God, or Nature - in order to contrast these statements with the old ones. The history of philosophy shows continuous efforts to obtain universal statements and the futility of these efforts due to the hopelessness of achieving the real universality of any statements. The historicity of knowledge helps to emphasize this process and brings the opportunity to draw a line from the past to the future state of art.

Bearing in mind the historicity of knowledge, the use of special semiotic resources shows the trends of strengthening the interaction of science and education in a globalized society. In general, 
knowledge is a set of learned concepts that ensure the formation of a description of reality. These concepts support the generalization of the cognitive process expressed through invariant structures. In this regard, the narratives supply reliability, and the possibility of repeating descriptions through collective forms of intellectual activity. These semiotic resources are associated with various cognitive practices and their basic propositional attitudes. Meanwhile, elements of scientific narratives often do not have the same meaning in contexts other than those in which these statements are originally formulated. For instance, in modern particle physics, it is permissible to consider the so-called 'magic numbers for nuclei' (cf. Mayer 1948; Audi 2006). Nonetheless, this statement does not mean that scientists recognize the equality of magic and science. Collective forms of activity create a context for the interpretation of the concepts used and guarantee the assimilation of knowledge through the interaction of research participants. Professional training helps to master the context of interpretation and expand it correctly.

As a result, in a globalized society, collective forms of intellectual activity increasingly determine the ways of developing scientific knowledge and education. In particular, the use of collective forms of intellectual activity can provide an exchange of narratives about the past, present, and future. These procedures increasingly depend on the orientation towards the expansion of the semiosphere and the building possible worlds at the intersection of science and education.

\section{Conclusion}

In this article, the analogy with behavior programming helps to reveal the author's conceptual outline of intellectual activity in culture and society. This approach helps to forecast the development of new forms of intellectual activity in a modern globalized society. Intellectual activity engages in the generation of worldbuilding narratives focused on the people's interaction. Narratives follow two rules, namely, (i) the use of speculations in worldbuilding, and (ii) a reflexive attitude to the images of the future.

Bearing in mind the rules of narrative making, the author of this article examines the use of new forms of intellectual activity in a globalized society. Since a globalized society is a complex of 
political, economic, and cultural ties that spread throughout the world, there is a unique situation of turning the world into a space of global communication and interaction. Social space requires an appropriate organization with proper decision-making methods. These methods depend on the forms of intellectual activity represented by the humanities as generators of new types of cultural achievements.

The author of this article reveals the connections between the concepts of intellectual activity in culture and its interpretation in terms of the semiosphere and die casting mechanism (Lotman et al. 1978; Lotman and Clark 2005). These metaphors supply a description of the generation, storage, transmission, and reception of information in society and culture as 'semiotic universe'. The processes in modern society and culture correspond to various forms of intellectual activity that are associated with the organization of data processing. As a result, the author considers the modern period as a cultural organization of data processing in terms of an analogue of technical device. This concept helps to assess the development of new forms of intellectual activity in a globalized society. From this angle, a globalized society becomes a place of communication, described by the humanities based on forms of collective intelligence and the exchange of narratives about the future. The author reveals the controversies of the key signs of intellectual activity in a globalized society. On the one hand, intellectual activity expresses tendencies towards making collective decisions. On the other hand, decisions are made due to the choice of people who take part in the activities of the die casting mechanism of culture, and they are dependent on it. In this regard, people do not really affect the decisions they make.

As a result, the author of this article examines the generalized understanding of intellectual activity in a globalized society. Forms of intellectual activity are related to the means of worldbuilding that cause the development of culture through the development of knowledge. With this in mind, the description of forms of intellectual activity helps to present the exchange of narratives about the future as a promising way of humanitarian research in a globalized society. The implementation of 
this exchange in the field of the intersection of scientific knowledge and education shows the possibilities of expanding the methodological arsenal for the reconstruction of images of the future. 


\section{Compliance with Ethical Standards}

\section{Disclosure of potential conflicts of interests}

\section{Funding: None}

Conflict of Interest: The author declares that he has no conflict of interest

\section{Research involving human participants and/ or animals}

a) Statement of human rights

Ethical approval: "All procedures performed in studies involving human participants were in accordance with the ethical standards of the institutional and/or national research committee and with the 1964 Helsinki declaration and its later amendments or comparable ethical standards."

b) Statement on the welfare of animals

Ethical approval: "This article does not contain any studies with animals performed by any of the authors."

\section{Informed consent:}

Informed consent: "Informed consent is obtained from all individual participants included in the study." 


\section{References}

Alward, P. (2011). Description, Disagreement, and Fictional Names. Canadian Journal of Philosophy, 41(3), 423-448. DOI: https://doi.org/10.1353/cjp.2011.0028

Audi, G. (2006). The History of Nuclidic Masses and of their Evaluation. International Journal of Mass Spectrometry. 251 (2-3): 85-94. DOI: https://doi.org/10.1016/j.ijms.2006.01.048

Barthes, R. (1957). Mythologies. Paris: Editions de Seuil.

Baudrillard, J. (1983). Simulations. Los Angeles, California: Semiotext(e).

Bauman, Z. (1998). Globalization: The Human Consequences. New York: Columbia University Press.

Calderón, J. C. P., \& Rainer, J. J. (2014). Global Collective Intelligence in Technological Societies: as a result of Collaborative Knowledge in combination with Artificial Intelligence. International Journal of Artificial Intelligence and Interactive Multimedia, 2(4), 76-80. DOI: https://doi.org/10.9781/ijimai.2013.249

Conrad, A. M., \& Munro, D. (2008). Relationships Between Computer Self-Efficacy, Technology, Attitudes and Anxiety: Development of the Computer Technology Use Scale (CTUS). Journal of Educational Computing Research, 39(2), 51-73. DOI: https://doi.org/10.2190/EC.39.1.d

Cronbach, L. J. (1957). The two Disciplines of Scientific Psychology. American Psychologist, 12 (11), 671-684. DOI: https://doi.org/10.1037/h0043943

Darwin, C. (1859). On the Origin of Species by Means of Natural Selection, or the Preservation of Favoured Races in the Struggle for Life. London: John Murray

Deleuze, G. (1990). Logic of Sense (M. Lester and C. Stevale, Trans.). London: Athlone Press. Depew, D.J., \& Weber, B.H. (2011). The Fate of Darwinism: Evolution After the Modern Synthesis. Biological Theory, 6(1), 89-102. DOI: https://doi.org/10.1007/s13752-011-0007- 
Donati, P. (2013). Relational Sociology and the Globalized Society. In: Dépelteau F., Powell C. (eds) Applying Relational Sociology (pp. 1-24). Palgrave Macmillan, New York. DOI: https://doi.org/10.1057/9781137407009_1

Eco, U. (1976). A Theory of Semiotics. London: Macmillan.

Eilstrup-Sangiovanni, M., \& Hofmann, Stephanie C. (2020). Of the Contemporary Global Order, Crisis, and Change. Journal of European Public Policy 27(7), 1077-1089. DOI: https://doi.org/10.1080/13501763.2019.1678665

Feldman, Z., \& Domshlack, C. (2014). Simple Regret Optimization in Online Planning for Markov Decision Processes. Journal of Artificial Intelligence, 51(2014), 165-205. DOI: https://doi.org/10.1613/jair.4432

Fermüller, C.G. (2008). Dialogue Games for Many-Valued Logics - an Overview. Studia Logica, 90(1), 43-68. DOI: https://doi.org/10.1007/s11225-008-9143-4

Frè, P.G. (2013). Stellar Equilibrium: Newton's Theory, General Relativity, Quantum Mechanics. In: Gravity, a Geometrical Course (pp. 237-271). Dordrecht: Springer. DOI: https://doi.org/10.1007/978-94-007-5361-7_6

Fisher, K., \& Fisher, M. D. (1997). The Distributed Mind: Achieving High Performance Through the Collective Intelligence of Knowledge Work Teams. New York: AMACOM.

Fischer, N., Mehnert, W. (2021). Building Possible Worlds: A Speculation Based Framework to Reflect on Images of the Future. Journal of Futures Studies, 25(3), 25-38. DOI: https://doi.org/10.6531/JFS.202103_25(3).0003

Flockhart, T. (2020). Is This the End? Resilience, Ontological Security, and the Crisis of the Liberal International Order. Contemporary Security Policy 41(2), 215-240, DOI: https://doi.org/10.1080/13523260.2020.1723966

Frigg, R. (2010). Models and Fiction. Synthese, 172(2), 251-268. DOI: https://doi.org/10.1007/s11229-009-9505-0 
Giddens, A. (2002). Runaway World. How Globalization is Reshaping our Lives (2nd edition). London: Profile Books.

Gent, I. P. (2013). Optimal Implementation of Watched Literals and More General Techniques. Journal of Artificial Intelligence, 48(2013), 231-252. DOI: https://doi.org/10.1613/jair.4016

Goody, J. (2010). From Oral to Written: An Anthropological Breakthrough in Storytelling. In Myth, Ritual and the Oral (pp. 117-152). Cambridge: Cambridge University Press. DOI: https://doi.org/10.1017/CBO9780511778896.009

Faris, N. (2019). Robots are coming for all of our sports - the only question is when. theScore https://www.thescore.com/mlb/news/1806003 Accessed 4 August 2021

Hegel, G. (1970). Hegel's Philosophy of Nature. (A.V. Miller, Trans.). Oxford: Clarendon Press. Hilton, E.N., Lundberg, T.R. (2021). Transgender Women in the Female Category of Sport: Perspectives on Testosterone Suppression and Performance Advantage. Sports Medicine 51(2), 199-214. DOI: https://doi.org/10.1007/s40279-020-01389-3

Hunt, E. (2006). The Mathematics of Behavior. New York: Cambridge University Press.

Hunt, E. (2010). Human Intelligence. New York: Cambridge University Press.

Ikenberry, G.J., \& Nexon, Daniel H. (2019). Hegemony Studies 3.0: The Dynamics of Hegemonic Orders. Security Studies 28(3), 395-421. DOI: https://doi.org/10.1080/09636412.2019.1604981

Kahn, C. (1979). The Art and Thought of Heraclitus: Fragments with Translation and Commentary. London: Cambridge University Press.

Kavalski, E. (2020). Inside/Outside and Around: Complexity and the Relational Ethics of Global Life. Global Society, 34(4), 467-486. DOI: https://doi.org/10.1080/13600826.2020.1745158

Ketko, T. (2020). Training Professional Humanities’ Teachers: A Controversial Study about Generic Methods. International Journal of Learning, Teaching and Educational Research, 19(8), 1-15. DOI: https://doi.org/10.26803/IJLTER.19.8.1 
Kotthoff, L. (2014). Algorithm Selection for Combinatorial Search Problems: A Survey. AI Magazine, 35(3), 48-60. DOI: https://doi.org/10.1609/aimag.v35i3.2460

Kovanović, V., Joksimović, S., Gašević, D., Siemens, G., \& Hatala, M. (2015). What Public Media Reveals about MOOCs: A Systematic Analysis of News Reports. British Journal of Educational Technology, 46(3), 510-527. DOI: https://doi.org/10.1111/bjet.12277

Koyré, A. (1966/1985). Études d'histoire de la pensée scientifique. Paris: Gallimard.

Kulikov, S.B. (2016a). Russian Way to the Knowledge-Based Society. Foresight 18(4), 379-390. DOI: https://doi.org/10.1108/FS-02-2016-0005

Kulikov, S. (2016b). Non-anthropogenic Mind and Complexes of Cultural Codes. Semiotica, 2016(213), 63-73. DOI: https://doi.org/10.1515/sem-2015-0034

Kulikov, S.B. (2021). Epistemic Relativism, Probability, and Forms of Subjectivity. Axiomathes. DOI: https://doi.org/10.1007/s10516-021-09565-4

Kurki, M. (2020). Multiplicity expanded: IR Theories, Multiplicity, and the Potential of TansDisciplinary Dialogue. Globalizations 17(3), 560-575, DOI: https://doi.org/10.1080/14747731.2019.1670532

Levy, P. (1999). Collective Intelligence. New York: Basic Books.

Lotman, Yu.; Uspensky, B.; \& Mihaychuk, G. (1978). On the Semiotics Mechanism of Culture. New Literary History. 9(2). 211-232. DOI: https://doi.org/10.2307/468571

Lotman, J., \& Clark, W. (2005). On the Semiosphere. Sign System Studies, 33(1), 205-229. DOI: https://doi.org/10.12697/SSS.2005.33.1.09

Marenbon, J. (2007). Medieval Philosophy: An Historical and Philosophical Introduction. London: Routledge

Mayer, M. G. (1948). On Closed Shells in Nuclei. Physical Review. 74(3): 235-239. DOI: https://doi.org/10.1103/physrev.74.235

Menzies, P., \& Pettit, P. (1994). In Defense of Fictionalism about Possible Worlds. Analysis, 54(1), 2736. DOI: https://doi.org/10.2307/3328100 
Metcalf, L., Askay, D. A., \& Rosenberg, L. B. (2019). Keeping Humans in the Loop: Pooling Knowledge through Artificial Swarm Intelligence to Improve Business Decision Making. California Management Review, 61(4): 84-109. DOI:

https://doi.org/10.1177/0008125619862256

Ogden, C. K. (ed.). (1932). Bentham's Theory of Fictions. New York: Harcourt, Brace and Company.

O’Neill, P. (1994). Fictions of Discourse: Reading Narrative Theory. Toronto: University of Toronto Press

Peirce, C. S. (1868). On a New List of Categories. Proceedings of the American Academy of Arts and Sciences, 7, 287-298.

Peirce, C. S. (1891/1892). Necessity, The Doctrine of-Examined. Monist, 2, 321-337.

Peters, M.A. (2021). Knowledge Socialism: The Rise of Peer Production - Collegiality, Collaboration, and Collective Intelligence. Educational Philosophy and Theory, 53(1), 1-9. DOI: https://doi.org/10.1080/00131857.2019.1654375

Salis, F. (2010). Fictional Reports. A Study on the Semantics of Fictional Names. Revista de Teoría, Historia y Fundamentos de la Ciencia, 25 (68), 175-185. DOI: https://doi.org/10.1387/theoria.634

Saussure, F. (1916/1997). Cours de Linguistique Générale. Saint-Germain, Paris VI: Payot \& Rivages.

Segaran, T. (2007). Programming Collective Intelligence: Building Smart Web 2.0 Applications. Sebastopol, California: O’Reilly Media

Slaughter, R. A. (2002). From Forecasting and Scenarios to Social Construction: Changing Methodological Paradigms in Futures Studies. Foresight, 4(3), 26-31. DOI: https://doi.org/10.1108/14636680210697731

Slowik, E. (2013). Newton's Neo-Platonic Ontology of Space. Foundations of Science, 18(3), 419448. DOI: https://doi.org/10.1007/s10699-011-9278-z 
Steel, S. (2012). Recovering Ancient and Medieval Contemplative Taxonomies as an Alternative to Bloom's Taxonomy of Educational Objectives. Paideusis - The Journal of the Canadian Philosophy of Education Society, 20(2), 46-56.

Tangen, J.M., Kent, K.M., \& Searston, R.A. (2020). Collective intelligence in fingerprint analysis.

Cognitive Research: Principles and Implications, 5(1), 23. DOI:

https://doi.org/10.1186/s41235-020-00223-8

Todt, O., \& Luján, J. L. (2014). Values and Decisions: Cognitive and Noncognitive Values in Knowledge Generation and Decision Making. Science, Technology \& Human Values, 39(5), 720-743. DOI: https://doi.org/10.1177/0162243914521019

Thomas Aquinas. (1911). The Summa Theologiae of St. Thomas Aquinas (Fathers of the English Dominican Province, Trans.). New York: Benzinger Brothers.

Vaihenger, H. (1910/1968). The Philosophy of 'As if': A System of the Theoretical, Practical and Religious Fictions of Mankind. (C. K. Ogden, Trans.) New York: Barnes and Noble.

Vernadsky, W. I. (1945). The Biosphere and the Noosphere. American Scientist, 33(1), xxii, 1-12. DOI: https://doi.org/10.2307/27826043

Zawacki-Richter, O., Kulikov, S.B., Püplichhuysen, D., \& Khanolainen, D. (2019). Russia. In: Zawacki-Richter O., Qayyum A. (eds.) Open and Distance Education in Asia, Africa and the Middle East. SpringerBriefs in Education (pp. 47-62). Singapore: Springer. DOI: https://doi.org/10.1007/978-981-13-5787-9_6

Zaidi, L. (2019). Worldbuilding in Science Fiction, Foresight and Design. Journal of Future Studies, 23(4), 15-26. DOI: https://doi.org/10.6531/JFS.201906_23(4).0003 